\title{
EN DEFENSA DEL ESTADO CONSTITUCIONAL DE DERECHO *
}

\author{
Josep Aguiló Regla \\ Universidad de Alicante \\ josep.aguilo@ua.es
}

RESUMEN. Tras caracterizar el Estado constitucional de Derecho y el proceso de constitucionalización de los órdenes jurídicos en el ámbito iberoamericano, el autor se centra en tres objeciones (la objeción contramayoritaria, la objeción a los derechos como principios y la objeción al judicialismo) que, en su opinión, ponen de manifiesto la incapacidad de parte de la cultura jurídica interna para adaptarse al Estado constitucional de Derecho. En consecuencia, considera urgente construir (y extender) el constitucionalismo jurídico: una teoría del Derecho adaptada al nuevo marco institucional.

Palabras-clave: Estado constitucional, constitucionalismo, democracia, principios, derechos, judicialismo, activismo judicial, constitucionalismo jurídico.

\section{In defense of the Constitutional Rule of Law}

ABSTRACT. After characterizing the "constitutional rule of law» states and the process of constitutionalization of legal systems in the Ibero-American sphere, the author discusses three difficulties (the counter-majoritarian one, the critique to viewing rights as principles, and the problem of judicial activism) that show the inability of part of the internal legal culture to assume the requirements of a constitutional rule of law. Consequently, the author considers it is urgent to build a legal constitutionalism: a theory of law adapted to the new institutional framework.

Keywords: constitutional state, constitutionalism, constitutional rule of law, democracy, principles, rights, judicial activism, legal constitutionalism.

* Fecha de recepción: 4 de noviembre de 2018. Fecha de aceptación: 13 de febrero de 2019.

Este texto reproduce la conferencia inaugural impartida en el marco del Primer Seminario Internacional de Argumentación Jurídica, Constitucionalismo y Democracia que, organizado por la Red Iberoamericana de Argumentación Jurídica (un foro de discusión jurídica creado por exalumnos del Máster de Argumentación Jurídica de Alicante), tuvo lugar en la Escuela Libre de Derecho (Ciudad de México) y en el Instituto de Investigaciones Jurídicas de la UNAM los días 29, 30 y 31 de octubre de 2018. 


\section{1. ¿POR QUÉ «EN DEFENSA»?}

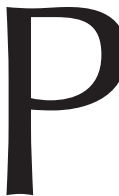

orque creo que el Estado constitucional de Derecho se halla en peligro, en riesgo de extinción. No se trata de hablar aquí de crisis constitucionales como la brasileña (originada por la destitución/golpe contra Dilma Rouseff) o la española (como consecuencia del embate independentista en Cataluña). No es eso lo que me preocupa. Cada una de esas crisis tiene componentes idiosincrásicos que la particulariza; aunque tal vez ocurra que no sean otra cosa que manifestaciones diferentes de un mismo fenómeno más general: la tendencia de las poblaciones actuales a polarizarse en frentes antagónicos e irreconciliables que hace imposible la práctica de una política democrático-deliberativa bajo el paraguas de una constitución. Sea como fuere, en esta lección quiero ocuparme de la incapacidad de gran parte de la cultura jurídica interna para atribuir valor civilizatorio al Estado constitucional de Derecho. Este valor proviene de algo tan sencillo como que el éxito de un Estado constitucional presupone que se haya producido la estabilización de las expectativas políticas y jurídicas en torno a dos cosas bien valiosas: la democracia política y la garantía de los derechos fundamentales. Y la responsabilidad de los juristas (o de muchos de ellos) proviene de socavar de manera contumaz la racionalidad que subyace al entramado institucional que llamamos Estado constitucional de Derecho; es decir, de la contumacia en privar de valor a la práctica jurídica generada al amparo de una constitución de un Estado constitucional. Para mostrarlo me centraré en tres grandes discusiones propias de la cultura jurídica interna (es decir, la de los juristas académicos y los profesionales del Derecho) que son el producto, en mi opinión, de una profunda incomprensión del valor del Estado constitucional. Me refiero a los debates en torno al carácter contramayoritario de las instituciones constitucionales, en torno a la caracterización de los derechos como principios y, finalmente, en torno al activismo judicial (la discusión entre formalismo y activismo judiciales). Naturalmente esta incomprensión de muchos juristas acaba teniendo consecuencias en las actitudes, valores y creencias de la cultura jurídica externa, es decir, de la gente en general.

Pero vayamos por partes. Empecemos por lo más básico, ¿qué cabe entender por Estado constitucional de Derecho?; continuemos por lo más próximo, es decir, el Estado constitucional en Iberoamérica; y, finalmente, abordemos algunos clichés de la cultura jurídica interna que erosionan la viabilidad jurídica del Estado constitucional.

\section{SOBRE EL ESTADO CONSTITUCIONAL DE DERECHO ${ }^{1}$}

\section{1. ¿De qué hablamos cuando hablamos de Estado constitucional de Derecho?}

No han sido pocos los autores (juristas y teóricos del Derecho) que han pretendido caracterizar al Estado constitucional de Derecho a partir de rasgos meramente

\footnotetext{
1 Lo que se va a decir en este epígrafe y el siguiente viene a ser un epítome de teoría constitucional extraído de trabajos míos anteriores. Entre otros: La constitución del Estado constitucional (Lima, Palestra, 2004), «Darse una constitución, tener una constitución y vivir en constitución» (en Isonomía, núm. 28, 2008, 67-86),
} 
estructurales. Según ellos, un Estado constitucional de Derecho se distinguiría por contar con una constitución rígida (de difícil o imposible modificación) y normativa (no meramente programática, sino que impone deberes directamente aplicables por los juristas en sus razonamientos jurídicos ordinarios). Vista así, la constitución cumple una función estrictamente conservadora pues impide el cambio jurídico: la lex superior de la constitución inhibe la lex posterior de la legislación. Naturalmente, lo anterior es cierto pero no es suficiente para caracterizar la constitución de un Estado constitucional, pues no todo Estado con una constitución rígida es un Estado constitucional. La rigidez y la normatividad constitucionales son garantías de algo distinto a ellas mismas; y el valor atribuido a «ese algo» es precisamente lo que dota de sentido y nos permite apreciar esas garantías. «Ese algo» no es otra cosa que los derechos del constitucionalismo. No toda constitución es una constitución del constitucionalismo porque no toda constitución garantiza los derechos del constitucionalismo.

\subsection{El constitucionalismo y los males potenciales de todas las dominaciones políticas}

2.2.1. Suele decirse que los ideales del constitucionalismo quedaron plasmados en el art. 16 de la declaración francesa de «derechos del hombre y del ciudadano» de 1789 al declarar que «una sociedad en la que la garantía de los derechos no está asegurada, ni la separación de poderes determinada, no tiene Constitución». Este es el tópico compartido desde el que suele partir cualquier explicación del constitucionalismo.

2.2.2. En mi opinión, sin embargo, la mejor manera de entender el constitucionalismo es mirarlo desde la perspectiva del compromiso con la denuncia de lo que podría llamarse el «seudoconstitucionalismo»: el uso del prestigio del constitucionalismo para ocultar las diversas formas de dominación política. Es decir, el seudoconstitucionalismo sería la forma ideológica (falseadora de la realidad) del constitucionalismo. Para ello, hay que dotar al constitucionalismo de un sentido liberador; erradicador de ciertos males potenciales, característicos y comunes, de todas las dominaciones políticas.

2.2.3. Hay cuatro males potenciales y característicos de toda dominación política. Estos males potenciales son universales: ningún sistema jurídico-político está definitivamente inmunizado frente a ellos. Por ello, el constitucionalismo arma a los ciudadanos con los derechos que operan como títulos que les permiten enfrentarse a esos males potenciales y característicos en las diversas formas en que puedan manifestarse. ¿Cuáles son esos males y esos derechos? ${ }^{2}$.

a) El mal de la arbitrariedad. Por definición, en la relación jurídico-política algunos están llamados a mandar y otros, a obedecer; por tanto, el ciudadano está sometido. Ahora bien, en la relación política legítima se está sometido solo a normas, no a personas. El mal potencial de la arbitrariedad consiste en verse sometido a la pura

\footnotetext{
«El constitucionalismo imposible de Luigi Ferrajoli» (en Doxa, núm. 34, 2011, 55-71), «Interpretación constitucional. Algunas alternativas teóricas y una propuesta» (en Doxa, núm. 35, 2012, 235-258).

2 Naturalmente el debate actual sobre el constitucionalismo abarca derechos que van más allá de los aquí referidos. Piénsese, por ejemplo, en los llamados derechos colectivos o en los derechos culturales, etc. Como es obvio, este debate no afecta a nuestra aproximación conceptual al Estado constitucional.
} 
voluntad de personas; y ninguna dominación política está inmunizada frente a ese mal. La medida higiénica para prevenir este mal es el reconocimiento de los derechos vinculados al imperio de la ley y/o al debido proceso. El sentido de estos derechos es dar un título («empoderar» se dice ahora) al ciudadano para que pueda defenderse frente a la arbitrariedad.

b) El mal del autoritarismo es la tendencia de quien tiene poder político a creer que su título le autoriza a ordenarlo todo: que puede regular cualquier cosa y que puede dotar a esa regulación de cualquier contenido. Frente a este mal potencial de la relación política se reconocen los llamados derechos de libertad. El sentido de tales derechos no es otro que el de generar esferas de inmunidad para el ciudadano que se traduzcan en incompetencias para el soberano. Los derechos de libertad dan un título permanente al ciudadano para combatir las inclinaciones al autoritarismo en cualquiera de las formas en que este se manifieste.

c) El mal del despotismo equivale al «sin el pueblo»; es decir, la tendencia de las dominaciones políticas a excluir a los ciudadanos de las decisiones políticas que les afectan. El mal del despotismo se concreta en la generación de excluidos políticos. Para que los ciudadanos puedan defenderse de esta tendencia a la exclusión se crean los llamados derechos democráticos o derechos de participación política que, como mínimo, aseguran al ciudadano un poder de remoción de las élites políticas.

d) El mal de la exclusión social. La exclusión política no es lo mismo que la exclusión social. Esta última se genera cuando aparecen colectivos de personas que no consiguen nunca que sus intereses sociales queden reflejados en esa peculiar composición de intereses sociales que llamamos «interés general». Para combatir este mal se crean los derechos sociales (y/o de igualdad real o de oportunidades) que no son otra cosa que intereses sociales que el sistema jurídico-político no puede dejar de satisfacer. Es decir, los derechos sociales tratan de asegurar ciertos intereses y oportunidades a todos los ciudadanos.

\subsection{El constitucionalismo de los derechos}

2.3.1. A este entramado de derechos suele llamársele «constitucionalismo de los derechos».

2.3.2. Si se analizan correctamente los derechos contemplados en $a$ ) y en $c$ ), es decir, los vinculados al debido proceso y los derechos democráticos, constituyen la concepción de la autoridad legítima del constitucionalismo. Ellos vienen a determinar quién y cómo puede ordenar legítimamente a los ciudadanos. Los derechos referidos en $b$ ) y en $d$ ), esto es, los derechos de libertad y los derechos sociales, vienen a constituir la concepción de la justicia del constitucionalismo. Es decir, vinculan a todos y sirven para determinar lo que no es legítimo prohibir ni obligar, y lo que no se puede negar (dejar de prestar) legítimamente a nadie. Establecen, por decirlo de alguna manera, contenidos imposibles y necesarios para el sistema jurídico-político.

2.3.3. Lo anterior significa que tanto la concepción de la autoridad legítima como la de la justicia están configuradas sobre la base de los derechos. Y ello constituye una gran novedad histórica que, usando los términos de BoBBIO, permite advertir que la 
relación política ya no es solo analizable ex parte principi (desde la parte del príncipe, del llamado a mandar), sino fundamentalmente ex parte populi (desde la parte del pueblo, de los llamados a obedecer). Si bien se considera, esta novedad histórica tiene un gran alcance civilizatorio.

2.3.4. El constitucionalismo de los derechos bien entendido implica dos cosas muy relacionadas entre sí. La primera es que los derechos cumplen esencialmente un papel de fundamentación dentro del sistema jurídico-político: fundamentan tanto la obligación política de los ciudadanos, esto es, el deber de obediencia (no en vano fundamentan la autoridad legítima), como los límites de dicho deber de obediencia (por cuanto fundamentan una idea de justicia que determina los contenidos necesarios e imposibles). La segunda es que la tradicional tensión entre autoridad y justicia se plantea de manera bien peculiar en el constitucionalismo de los derechos: pues tanto la autoridad legítima como la justicia encuentran su fundamento en los derechos de los gobernados.

\subsection{De nuevo sobre el Estado constitucional de Derecho}

2.4.1. Los derechos son, pues, aquello que dota de sentido y valor a la rigidez (la lex superior destinada a inhibir la lex posterior) y a la normatividad (los vínculos materiales) de la constitución. Sin el valor de los derechos, esas propiedades (esas garantías) simplemente no se entienden y resultan insoportables.

2.4.2. Ahora bien, esas mismas propiedades plantean al constitucionalismo un dilema aparentemente irresoluble. Si el constitucionalismo no se hace rígido y normativo, entonces no garantiza los derechos; pero si se hace rígido y normativo, entonces «somete a los vivos a la tiranía de los muertos».

2.4.3. Se ha escrito muchísimo sobre este dilema. En mi opinión, solo hay una salida: atribuir a los derechos un papel de fundamentación y atribuir a la práctica constitucional un rol esencialmente interpretativo de dichos derechos. La forma, pues, de evitar los términos indeseables de «ausencia de garantía de los derechos» y de «sometimiento de las generaciones vivas al pasado» consiste en analizar la continuidad de la práctica constitucional en términos interpretativos de los derechos. Ello se traduce necesariamente en un equilibrio razonable entre rigidez (impedimento del cambio) y apertura regulativa (adaptabilidad interpretativa); continuidad del valor y adaptabilidad interpretativa de las normas que lo garantizan.

2.4.4. La idea de constitución así entendida connota lo fundamental (los derechos), lo permanente, lo estable, el marco compartido, el consenso, lo indisponible para todos, lo asegurado a todos, etc. Ahora bien, para que una constitución pueda connotar todo eso tiene que haber resuelto dos problemas básicos: el problema del consenso y el del compromiso.

- El problema del consenso es que la constitución tiene que unir a las poblaciones y a las diferentes facciones políticas en torno a un texto. Sin aceptación, difícilmente puede haber constitución. En múltiples ocasiones, alcanzar el consenso exige recurrir a una regulación de principios y a la formulación de cláusulas normativas abiertas. 
- El problema del compromiso consiste en lo siguiente: el éxito de una constitución pasa necesariamente por su permanencia en el tiempo (pues se considera que hay algo contradictorio entre la idea de constitución y la de su continua revisión) y, sin embargo, tenemos dificultades para atarnos normativamente hacia el futuro (tenemos inseguridad práctica respecto de lo que consideraremos correcto en el futuro, respecto de los vínculos normativos a asumir). Esta tensión entre la necesidad de permanencia en el tiempo y la dificultad para concretar los compromisos normativos hacia el futuro explica la necesidad de recurrir en muchas ocasiones a una normatividad saturada de principios y de conceptos valorativos.

2.4.5. Lo que en el momento de «darse una constitución» se ve como problemas de consenso y de compromiso; se ve como problemas de interpretación de principios en el momento de usar y/o de «aplicar una constitución». Si tiene sentido acudir a principios y cláusulas abiertas para resolver los problemas de consenso y de compromiso en el momento de darse una constitución, tiene que tener sentido interpretarlos en el momento de su aplicación. En ocasiones, pues, la regulación abierta de las constituciones no es un defecto, es más bien una necesidad práctica: se trata, en realidad, de estabilizar una práctica deliberativa e interpretativa en torno a los derechos, donde estos juegan un papel de fundamentación. Ello muestra de manera patente las diferencias entre una constitución y una ley. Lo que es virtud en la constitución (p. ej., la regulación abierta), puede resultar un grave defecto de la ley; y a la inversa.

\section{SOBRE EL ESTADO CONSTITUCIONAL EN IBEROAMÉRICA}

Todo lo dicho hasta ahora es aplicable a casi todos los órdenes jurídicos que llamamos Estados constitucionales. Ahora bien, hay algo que es predicable de los Estados constitucionales iberoamericanos (aunque no solo de ellos) y que, sin embargo, no es predicable de otros Estados constitucionales. Me refiero al proceso conocido como la «constitucionalización del orden jurídico».

\subsection{El proceso de constitucionalización del orden jurídico}

3.1.1. Los Estados constitucionales en Iberoamérica cuentan, como todos los demás, con una constitución rígida y normativa que asume los parámetros valorativos del constitucionalismo de los derechos. Pero se caracterizan también por ser Estados que provienen de una cultura jurídica legalista, de la tradición del Civil Law. Ello significa que en estos países el ideal jurídico y político del Estado de Derecho se ha construido tradicionalmente en torno a la idea del «imperio de la ley». Son Estados constitucionales porque cuentan con una constitución con las características antes mencionadas, pero en los que el razonamiento jurídico ha sido tradicionalmente solo sub lege. Conforme a este modelo tradicional, el razonamiento jurídico ordinario no quedaba penetrado por argumentos de naturaleza constitucional porque la legislación constituía el umbral del marco jurídico de referencia para el jurista.

3.1.2. Ello ha supuesto que todos los Estados constitucionales de la zona han emprendido en diferentes grados e intensidades un proceso de constitucionalización de 
sus órdenes jurídicos. Por decirlo en términos descriptivos: a medida que los juristas van introduciendo argumentos constitucionales en la resolución de sus casos ordinarios, se va produciendo el fenómeno de la constitucionalización ${ }^{3}$. El dictum: «De la interpretación de la constitución conforme a la ley a la interpretación de ley conforme a la constitución» expresa de manera contundente y sintética las implicaciones y el alcance del referido proceso de constitucionalización.

3.1.3. Como cuestión de hecho, el fenómeno de la constitucionalización no puede ser negado; y, en realidad, nadie lo niega. Otra cosa es la valoración que se haga del mismo.

\subsection{La valoración del proceso de constitucionalización}

3.2.1. No han sido pocos los autores que en este proceso solo han visto un traslado de poder desde el legislativo al judicial. Es decir, del poder de los legisladores al poder de los jueces y, en consecuencia, han considerado que se estaban debilitando las exigencias normativas derivadas del «gobierno de las leyes» y que se estaba retrocediendo hacia esquemas vetustos vinculados al «gobierno de los hombres» (de las élites intelectuales y judiciales). El Derecho - dirán estos críticos del proceso de constitucionalización - está dejando de ser general (pues la aplicación de los principios constitucionales acaba desembocando en el Derecho del caso), claro (la aplicación de principios implica un razonamiento jurídico que no es puramente deductivo), coherente (los principios constitucionales son contradictorios entre sí y no cabe establecer prioridades estables entre ellos), etc. La crítica, en definitiva, consiste en afirmar que la referida evolución supone un retroceso «civilizatorio», pues se estarían minando las bases sobre las que estaban construidos los valores de la autonomía de las personas y de la seguridad jurídica, dando entrada a la arbitrariedad y al decisionismo en la aplicación del Derecho.

3.2.2. Pero esta no es la única forma de verlo. Muchos juristas hemos valorado positivamente esta evolución y hemos asumido la constitucionalización de nuestros órdenes jurídicos como un proyecto. Como una gran oportunidad para mejorar (civilizar) nuestras prácticas jurídicas. Si bien se considera, una buena parte del trabajo intelectual del grupo de Filosofía del Derecho de la Universidad de Alicante ha consistido en tratar de contribuir a construir una teoría del Derecho adaptada a ese proceso de constitucionalización; y ese empeño provenía de la conciencia de oportunidad. Y por qué no decirlo también: siempre hemos pensado que el proyecto docente del «Máster de argumentación jurídica de Alicante» tenía una dimensión política clara: extender la conciencia de la oportunidad de mejora de nuestras prácticas jurídicas que implicaba el proceso de constitucionalización. Y otro tanto puede decirse de nuestra participa-

3 R. Guastini, Lezioni di teoria del diritto e dello Stato, Torino, G. Giappichelli editore, 2006, 239 y ss. «En un orden jurídico no constitucionalizado —escribe GUASTINI - el Derecho constitucional [...] tiene un radio de acción limitado: por un lado, disciplina los aspectos fundamentales de la organización del Estado (la distribución de los poderes legislativo, ejecutivo y judicial [...]); por otro, determina los derechos de libertad de los ciudadanos frente a los poderes públicos [...] Por el contrario, en un orden constitucionalizado, el Derecho constitucional tiende a ocupar todo el espacio de la vida social y política, condicionando la legislación, la jurisprudencia, el estilo doctrinal, las acciones de los actores políticos, las relaciones privadas» (p. 240). 
ción en el proyecto de la I-Latina (Iusfilosofía del mundo latino). No hace falta aclarar que no es lo mismo valorar positivamente ese proceso que dar por bueno todo lo que se ha hecho en nombre de un supuesto «nuevo constitucionalismo latinoamericano». Aquí no voy a referirme a él, pero sí quiero mostrar todas las distancias respecto del mismo. En cualquier caso y a modo de conclusión puede decirse que la correcta constitucionalización del orden jurídico, en la medida en que ha supuesto una estabilización de las expectativas jurídicas y políticas en torno a la democracia y a la deliberación sobre el alcance de los derechos fundamentales, ha producido una mejora indudable de nuestras prácticas jurídicas.

3.2.3. Aunque no voy a detenerme aquí en ello, lo mismo puede decirse, me parece, del proceso de internacionalización del constitucionalismo de los derechos y de su jurisdicción. Habrá luces y sombras, pero su balance es netamente positivo. Piénsese simplemente en las implicaciones que tiene para el mundo jurídico la abolición de la doctrina de los «asuntos internos» para referirse a las violaciones de los derechos humanos y el abandono de las lecturas meramente idiosincrásicas de los mismos.

\section{TRES INCOMPRENSIONES DE LOS JURISTAS QUE LASTRAN LA CONSOLIDACIÓN DEL ESTADO CONSTITUCIONAL DE DERECHO}

\subsection{La objeción contramayoritaria}

4.1.1. En mi opinión, en los últimos tiempos, la cuestión de la legitimidad democrática tiende a plantearse en términos un tanto sesgados por influencia de las concepciones meramente procedimentalistas de la democracia. En efecto, en muchas ocasiones se sostiene que solo donde rige la regla de la mayoría puede hablarse de legitimidad democrática, mientras que las instituciones que se rigen por otros criterios de legitimidad no son democráticas (o dudosamente lo son). Naturalmente, la llamada objeción contramayoritaria pone en jaque la estructura misma del Estado constitucional, pues por definición la constitución rígida rompe la regla de las mayorías y sus dos principios básicos: «un hombre un voto» y «todos los votos valen lo mismo». Si la constitución es rígida, el voto del que quiere conservar la constitución vale más que el voto del que quiere cambiarla. Ello naturalmente se ha utilizado para debilitar la legitimidad democrática del Estado constitucional.

4.1.2. Lo anterior constituye, me parece, un error; error que consiste en identificar legitimidad democrática con «deber de representación política». En efecto, hay muchas instituciones democráticas cuya legitimidad pende del hecho de que sus integrantes cumplan con sus «deberes de representación» de intereses sociales. Todas las instituciones representativas, aquellas cuya legitimidad está vinculada a la representación política, se rigen por criterios mayoritarios. En ellas se trata de componer «el interés general» a partir de la representación de intereses de grupos sociales considerados legítimos. Esta es, sin duda, una parte muy importante de la legitimidad democrática; pero solo una parte. En relación con ella, los males por antonomasia son la exclusión política y la exclusión social. Pero hay otras instituciones, como pueden ser los casos de 
los tribunales supremos, constitucionales o internacionales, que se rigen por criterios de legitimidad que nada tienen que ver con las mayorías, la representación política ni la «negociación» del «interés general». Que ello sea así no disminuye ni un ápice su legitimidad democrática. La tarea de estas instituciones está vinculada al control de la exclusión política (la violación de los derechos de participación política), por un lado, y de la violación de los derechos (de los límites) en la negociación política, por otro. Nótese que es un lugar común definir los derechos fundamentales como lo que debe quedar fuera de toda negociación política, lo protegido frente a la negociación, lo no negociable. En consecuencia, la democracia fundada en derechos es también contramayoritaria: la democracia no es disponible «por la mayoría». Pues bien, en mi opinión, tan democrática es la aceptación de la regla de la mayoría como el reconocimiento de derechos (de lo no negociable, de lo no disponible); tan democrático es el deber de representación de intereses sociales de las autoridades políticas como el deber de independencia (prohibición de representación de intereses sociales) de las autoridades jurisdiccionales. En abstracto, la división del trabajo entre legisladores y jueces «constitucionales y/o internacionales» en el marco de un Estado constitucional no me parece particularmente problemática en términos de legitimidad. Naturalmente, ello no significa que no haya problemas, sino que los problemas deben de situarse en otra parte.

4.1.3. En el ámbito del Estado de Derecho, la independencia (autoridades jurisdiccionales) como criterio de legitimidad se construye esencialmente en oposición a los otros dos grandes criterios de legitimidad, la representación (autoridades políticas) y la sujeción (autoridades administrativas). En efecto, en el Estado de Derecho la legalidad de la actuación es condición necesaria para la justificación (legitimidad) de la acción de cualquier órgano público. Ahora bien, las autoridades administrativas además tienen entre otros un deber de sujeción, es decir, un deber de obediencia a sus superiores. Luego los juicios de legitimidad de su actuación incorporan entre otros elementos una combinación de juicios de legalidad y de sujeción. Las autoridades políticas, a su vez, tienen entre otros un deber de representación de intereses sociales. En consecuencia, los juicios de legitimidad respecto de su actuación incorporan también una combinación de juicios de legalidad y de representación. La legitimidad de las autoridades jurisdiccionales gira también en torno a la legalidad, pero el deber de independencia se construye esencialmente en oposición a los otros dos criterios de legitimidad recién mencionados. El deber de independencia prohíbe, por un lado, someterse a personas, es decir, la sujeción (el actor independiente solo tiene permitido someterse a normas); y, por otro, cumplir funciones de representación de grupos y/o intereses sociales (el actor independiente tiene prohibido representar intereses propios o ajenos).

4.1.4. Los problemas de legitimidad democrática se producen cuando los ciudadanos perciben que una determinada institución «traiciona» los criterios de legitimidad que le son propios. La legitimidad democrática padece siempre que los ciudadanos perciben que sus «representantes» no les «representan» porque incumplen el deber de velar por sus intereses (es decir, cuando desconfían y sospechan que sus representantes velan por «intereses inconfesables»). Pero la legitimidad democrática padece también cuando los llamados a dirimir ciertas contiendas desde la indepen- 
dencia son percibidos como representantes; es decir, cuando los jueces que deben controlar los límites de lo negociable políticamente son percibidos como una mera extensión de la representación política (es decir, cuando los ciudadanos desconfían de su independencia). En mi opinión, atenta tanto contra la legitimidad democrática el incumplimiento del deber de representación en el ámbito en el que rige este principio, como el incumplimiento del deber de independencia en su respectivo ámbito ${ }^{4}$.

\subsection{La objeción a los derechos como principios constitucionales}

4.2.1. Muchos juristas piensan que considerar que los derechos son principios debilita su normatividad porque los somete al riesgo permanente de ser derrotados a través de la ponderación. Quienes así piensan no entienden, me parece, los derechos, los principios ni la ponderación. Pero vayamos por partes.

4.2.2. Entender bien los principios, en oposición a las reglas, supone reconocer tres cosas. La primera es que los principios, al igual que las reglas, son normas regulativas que imponen deberes. El principio de igualdad, por ejemplo, es perfectamente formulable en términos deónticos como la «prohibición de discriminar». La segunda es que, a diferencia de las reglas, los principios no definen un caso genérico mediante propiedades descriptivas que excluyan la deliberación práctica en el momento de su aplicación. En consecuencia, al no definir caso, todo razonamiento de principios implica siempre una deliberación respecto de la relevancia o no del principio para el caso que se trata de resolver. Y la tercera es que los principios cumplen un papel de fundamentación en relación con las reglas; las dotan de un sentido protector y/o promocional de ciertos bienes jurídicos.

4.2.3. Lejos de lo que inopinadamente suele repetirse, los principios no debilitan a las reglas. Y no lo hacen porque el punto de partida es que toda regla expresa ya una ponderación de principios y, en consecuencia, tiene siempre una justificación: tiene un sentido protector y/o promocional de ciertos bienes jurídicos. Por ello, la ponderación es, en realidad, una operación anterior y más básica que la subsunción; pues toda regla presupone ya una ponderación. No hace falta insistir en que no se trata de una cuestión de hechos, sino de método: en los hechos no hay forma de dirimir si una regla expresa únicamente una voluntad o también una ponderación. Este punto es fundamental porque acaba afectando a todas las operaciones del método jurídico que tengan que ver con la idea de «correcta aplicación del Derecho (de las reglas)». Todas esas operaciones guardan relación con la noción de «lealtad a las reglas», de «aplicación leal de las reglas»: ¿Ser leal a una regla es serlo solo a su expresión lingüística o serlo también a la ponderación que la justifica? O la misma distinción entre casos fáciles y casos difíciles se ve afectada por la alternativa anterior: ¿la facilidad/dificultad de un caso en relación con su premisa normativa, depende solo de cuestiones semánticas o

${ }^{4}$ En este punto, no quiero dejar de referirme al tribunal constitucional español. Lleva diez años sin dictar sentencia declarando la constitucionalidad de la ley del aborto. ¿Por qué no lo hace? Cualquier explicación que quiera darse pasa por la falta de independencia de algunos de sus magistrados que indebidamente desempeñan funciones de representación de intereses políticos y/o religiosos. Lo que naturalmente acaba erosionando su legitimidad democrática, pero no por ser contramayoritarios, sino por falta de independencia. 
también de cuestiones valorativas? ¿La facilidad de un caso depende de la claridad semántica de la regla a aplicar, o de la nitidez de su justificación para el caso a resolver? Los principios no debilitan a las reglas, sino que, muy al contrario, las dotan de sentido práctico.

4.2.4. Otra cosa es que el ámbito justificativo de un principio quede saturado por las reglas que desarrollan ese principio en un momento determinado. Aceptar la normatividad de los principios implica aceptar que las reglas no siempre saturan el ámbito justificado de aplicación de un principio. Por ello, para razonar jurídicamente en términos de principios hay que haber detectado y justificado la existencia de alguna forma de laguna en el nivel de las reglas, pues solo se apela a los principios si se detectan problemas en la aplicación de las reglas. En consecuencia, puede decirse que quien invoque un principio frente a una regla corre siempre con la carga de la justificación. Ello supone mostrar dos cosas: por un lado, que la regla en cuestión tiene sentido práctico, que está orientada a proteger algo valioso; y, por otro, que en el caso en cuestión la regla no es aplicable porque decae su sentido práctico. Todo ello significa que las reglas no permanecen completamente cerradas (insensibles, opacas, etc.) a los principios que las justifican y que el desplazamiento de las mismas supone siempre la formulación de una nueva regla.

4.2.5. Si se entiende lo anterior, entonces se está en condiciones de entender por qué se dice que los derechos constitucionales son principios. La razón es bloquear la tesis positivista de la correlatividad entre derechos y deberes. Dicha tesis puede formularse así: «Los enunciados jurídicos de derechos relativos a un sujeto o una clase de sujetos son siempre reducibles a enunciados de deberes de otro u otros sujetos». Decir que alguien tiene un derecho puede traducirse, sin pérdida de significación, a enunciados de deber de otro u otros sujetos. Derechos y deberes son, pues, correlativos. En un sentido trivial, puramente regulativo, es cierto que los derechos son traducibles a enunciados de deberes. Pero en sentido justificativo la correlatividad entre derechos y deberes se pierde y, en consecuencia, los enunciados de derechos no son traducibles a enunciados de deberes simplemente transponiendo (invirtiendo) los sujetos de la relación. La transposición sí supone pérdida de significación porque mientras que tiene pleno sentido afirmar que «alguien tiene un deber porque otro tiene un derecho», no parece ocurrir lo mismo con la afirmación de que «alguien tiene un derecho porque otro tiene un deber». El «reconocimiento» de derechos justifica la «imposición» de deberes, mientras que la imposición de deberes no sirve para justificar la titularidad de los derechos.

4.2.6. Los derechos son principios porque son los títulos que justifican la imposición a otros de deberes orientados a garantizarlos. Este carácter de título que tienen los derechos hace que nunca queden saturados por las reglas que en un momento determinado los garantizan. Si bien se considera, el progreso en materia de derechos no consiste tanto en reconocer nuevos derechos cuanto en mejorar las reglas, los deberes que tratan de garantizarlos (las técnicas de protección de los mismos) ${ }^{5}$.

5 Por sorprendente que pueda resultar, F. LAPORTA ha jugado un papel muy importante a propósito de esta forma de concebir la relación entre derechos fundamentales y deberes. Su texto «Sobre el concepto de derechos humanos» (en Doxa, núm. 4, 1987, 23-46) está en el origen del pospositivismo de muchos de nosotros. 


\subsection{La objeción al judicialismo (la polémica formalismo vs. activismo judiciales)}

4.3.1. Con gran frecuencia se oye decir que el «nuevo Derecho», el que es un producto de la constitucionalización del orden jurídico, lo único que hace es permitir que los jueces se escapen de la legalidad, de las exigencias formales derivadas del imperio de la ley. Entre los principios, la ponderación y los derechos, algunos jueces tendrían a su disposición todos los recursos necesarios para saltarse las exigencias formales de sus decisiones y atacar directamente las exigencias de justicia derivadas de los derechos fundamentales y/o de los principios constitucionales. Este es el problema que plantea el activismo judicial.

4.3.2. Así surge el debate entre la alternativa «formalismo judicial» frente a «activismo judicial». El juez formalista sería un juez apegado a la legalidad y desapegado de la constitucionalidad; y el juez activista sería un juez desapegado de la legalidad y apegado a la constitucionalidad (comprometido con la realización de los valores constitucionales). Me interesa destacar que, más allá de otros posibles usos de estas expresiones, en este contexto se usan ambas de forma descalificatoria. Tienen carga emotiva negativa: se acusa/critica a un juez concreto de formalista o activista para mostrar que su decisión se aparta del Derecho bien entendido. Se usa, pues, de forma evaluativa, no descriptiva. Un juez formalista sería un mal juez; un juez activista sería también un mal juez. Planteada así la discusión parece que hubiera que elegir entre males; o peor, quedarse con ambos. La situación recuerda el proverbio judío de que «al elegir entre males, el pesimista elige ambos». En mi opinión, todo ello está mal planteado y conlleva un sinfín de enredos conceptuales.

4.3.3. El primer enredo $-\mathrm{y}$ del que derivan algunos otros- tiene que ver con que «formalismo» y «activismo» no son, en sentido estricto, opuestos conceptuales ${ }^{6}$. Para la cultura jurídica, lo que en realidad se opone a «formalismo» es «sustantivismo». No vamos a descubrir ahora la ambigüedad de las palabras y, por tanto, es posible que algunos autores usen los términos «formalismo»/«activismo» de manera que sí quepa afirmar dicha oposición. Este no es el problema, sino que inadvertidamente se vayan produciendo deslizamientos de significado que acaben distorsionando la discusión. Tratemos, pues, de poner orden.

4.3.4. Formalismo se opone a sustantivismo; el formalismo prioriza las razones formales, y el sustantivismo, las razones sustantivas o materiales. En este sentido, la oposición entre formalismo y sustantivismo es ineliminable dentro del razonamiento jurídico. Y, por ello, la oposición entre uno y otro es un ingrediente necesario del Derecho. Pretender prescindir de uno de los dos sería tanto como cercenar un componente esencial.

4.3.5. La explicación de la decisión judicial puede verse como el efecto combinado de la «conciencia jurídica formal» y de la «conciencia jurídica material». Como explicaba Ross: «Puede decirse así que la administración de justicia es la resultante

${ }^{6}$ Cfr. J. J. LEÓN, «Formalismo y activismo judicial en la argumentación constitucional», ponencia presentada al Seminario de Teoría del Derecho de Fin de Mundo: «Juicio a los tribunales: aplicación, decisión y creación del derecho», que tuvo lugar en Santiago de Chile en agosto de 2018. 
de un paralelogramo de fuerzas en el que los vectores dominantes son la conciencia jurídica formal y la conciencia jurídica material. La decisión a que se arriba está determinada por el efecto combinado de la interpretación cognoscitiva de la ley y de la actitud valorativa de la conciencia jurídica» ${ }^{7}$. Por ello, la discusión sobre la mejor decisión jurídica será siempre el resultado de cómo «tiran del cuerpo esos dos vectores». Del mismo modo que la noción de fuerza centrífuga necesita, para su comprensión, de la de fuerza centrípeta, formalismo y sustantivismo, vistos como fuerzas que tiran de la decisión judicial, se necesitan recíprocamente; y, como es obvio, ninguno de los dos términos tiene connotaciones críticas o peyorativas. Tratemos de mostrarlo.

4.3.6. Tomemos y enfrentemos dos modelos de buen juez debidos a dos autores bien conocidos por todos nosotros. El modelo de Francisco LAPORTA y el de Manuel ATIENZA.

4.3.6.1. El juez ideal de LAPORTA ${ }^{8}$ sería un juez deferente al legislador, partidario del modelo de las reglas (y del literalismo en su interpretación) y muy cauteloso con el recurso a los principios y a la ponderación. En este sentido, sería expresión de la conciencia jurídica formal dentro del Estado constitucional; pero si se lee bien a LAPORTA, se verá que la «conciencia jurídica material» no queda excluida del marco del razonamiento jurídico legítimo: el juez ideal de LAPORTA no es un juez ciego a los problemas sustantivos que puedan generarse por la aplicación de las reglas.

4.3.6.2. El juez ideal de ATIENZA ${ }^{9}$ es un juez que toma las mejores decisiones (las más justas) sin abandonar nunca los límites del Derecho. En este sentido, es partidario de un juez activo que, más que deferente, debe ser consciente de sus límites; y dentro de estos límites no duda en recurrir a los principios y la ponderación para tomar las mejores decisiones, las correctas, las justificadas. Este juez, que vendría a ser la expresión de la «conciencia jurídica material» dentro del Estado constitucional, no es en absoluto insensible a las razones formales: el juez ideal de ATIENZA es un juez bien consciente de los límites formales del Derecho a la hora de impartir justicia.

4.3.6.3. Estos dos autores han discutido entre ellos y discrepan respecto del ideal de juez. No voy a reproducir aquí los argumentos. Lo interesante, sin embargo, es que ninguno de ellos considera que el modelo de juez de su interlocutor sea ilegítimo en términos jurídicos. El tipo de relación que se daría entre dos jueces que reunieran sus respectivas características sería más o menos esta: $a$ ) En un porcentaje altísimo de casos rutinarios estarían de acuerdo; pondrían la misma sentencia y/o deliberando entre ellos alcanzarían la misma solución. b) En algunos casos especialmente difíciles es plausible pensar que no alcanzarían la misma solución; y que, por tanto, dependiendo de la posición que ocupasen, se formularían respectivamente votos particulares o en disidencia. Ahora bien, aun discrepando respecto de lo correcto se reconocieran recíprocamente plena legitimidad. Y c) ambos jueces estarían completamente de acuerdo en la detección de casos de conducta judicial ilegítima o desviada; es decir, de casos en

\footnotetext{
7 A. Ross, Sobre el Derecho y la justicia (trad. de G. Carrió), 2. ${ }^{a}$ ed., Buenos Aires, Eudeba, 1970, 134.

8 F. LAPORTA, El Imperio de la ley. Una visión actual, Madrid, Trotta, 2007.

9 M. AtienZA, «Diez tesis sobre el razonamiento judicial», en J. Aguiló Regla y P. Grandez (eds.), Sobre el razonamiento judicial. Una discusión con Manuel Atienza, Lima, Palestra, 2017.
} 
los que un juez se saltase bien los límites del Derecho, bien los sentidos y/o propósitos mínimos del mismo.

4.3.7. ¿Qué se sigue de todo lo anterior? Tres cosas, me parece:

4.3.7.1. Que la oposición entre formalismo y sustantivismo es ineliminable dentro del pensamiento jurídico y que ambos son «fuerzas» que, cuando se manifiestan, apuntan generalmente a soluciones diferentes. En este sentido, los ideales de juez encarnarán inevitablemente la prevalencia bien de la «conciencia jurídica formal», bien de «la conciencia jurídica material».

4.3.7.2. Que, con independencia del ideal de juez que se asuma, la inmensa mayoría de casos tiene una solución correcta y aceptable para todos los participantes «no demediados». Se trata de los llamados casos fáciles o rutinarios.

4.3.7.3. Y que, con independencia del ideal de juez que se asuma, es relativamente fácil ponerse de acuerdo respecto de los casos de conducta judicial desviada.

4.3.8. Lo anterior lleva a distinguir tres tipos de casos o situaciones: a) casos fáciles (ambos modelos de juez estarían de acuerdo en la decisión a tomar); b) casos difíciles (tal vez no se pondrían de acuerdo y discreparían respecto de la respuesta correcta, pero se reconocerían recíprocamente legitimidad: habría controversia respecto de la decisión a tomar y respetuosos votos en disidencia), y c) casos de desviación judicial (ambos jueces estarían de acuerdo en la detección de conductas judiciales que constituyeran «decisiones judiciales desviadas»).

4.3.9. La conducta judicial desviada.

4.3.9.1. Como es sabido, Robert K. MERTON clasificaba en cinco formas diferentes la adaptación de los individuos a los grupos sociales; y lo hacía a partir de la aceptación o el rechazo tanto de los fines definidos culturalmente (cultural goals) como de los medios institucionales (institutionalized means) predispuestos para alcanzarlos ${ }^{10}$. Así, distinguía: 1) La conformidad: acepta los fines y los medios. 2) La innovación: acepta los fines pero rechaza los medios. 3) El ritualismo: rechaza los fines pero acepta los medios. 4) La apatía (retreatism): rechaza tanto los fines como los medios, pero no propone alternativas. 5) La rebelión: rechaza tanto los fines como los medios, pero propone fines y medios alternativos. Si bien se considera, esta clasificación permite recapitular y redefinir todo lo dicho hasta ahora.

4.3.9.2. La discusión entre formalismo y sustantivismo representada por los dos modelos ideales de juez de LAPORTA y de ATIENZA es una discusión entre concepciones diferentes de la conformidad: se trata de dos formas de interpretar la conducta judicial conforme; son dos interpretaciones diferentes de lo que significa aceptar los medios (las formas jurídicas) y los fines (los valores a proteger). El «juez deferente» y el «juez activo» son dos concepciones diferentes del «juez correcto».

4.3.9.3. Cuando las expresiones «formalismo» y «activismo» se usan peyorativamente, para descalificar la conducta de un juez, se están usando para referirse a dos formas diferentes de conducta judicial desviada. El formalismo vendría a equivaler al

10 Cfr. R. K. MerTON, «Social Structure and Anomie», American Sociological Review, vol. 3, núm. 5 (oct. 1938), 676 y ss. 
ritualismo como conducta judicial desviada: acepta los medios predispuestos por el Derecho (las formas jurídicas) pero rechaza los fines a perseguir (pues, según él, no hay valores sustantivos que proteger separados de los medios predispuestos). El activismo vendría a equivaler a la innovación judicial como conducta desviada: acepta los fines perseguidos por el Derecho (los derechos, principios, etc.) pero innova/rechaza los medios predispuestos por el Derecho para alcanzarlos (las formas jurídicas).

4.3.10. Si se tiene claro lo anterior, es fácil comprender por qué la cuestión «formalismo $v s$. activismo» es un caso de discusión mal planteada:

4.3.10.1. Si se trata de dos casos de conducta desviada, entonces no tiene sentido elegir: lo que habrá que hacer es denunciar a ambos como «males» de nuestra práctica judicial. Podrán discutirse cuestiones tales como cuál de los dos vicios es más grave o si «nuestros jueces» incurren de hecho más en uno u otro de los vicios, pero poco más.

4.3.10.2. Si se trata de una discusión entre dos modelos ideales de juez, estaremos entonces ante una genuina discusión de «ética judicial» relativa a la excelencia judicial: ¿Cuánto pesan la «conciencia jurídica formal» y la «conciencia jurídica material» en los ideales de excelencia judicial? Esta discusión naturalmente no puede versar sobre un juez «demediado»: quedan fuera de la misma tanto el juez ritualista por formalista como el juez innovador por activista.

4.3.10.3. El efecto combinado de las dos discusiones anteriores conlleva que los discursos más comunes sean contra un «hombre de paja»: se enfrenta un modelo de excelencia judicial con un prototipo de conducta desviada. Se contrapone, por ejemplo, el juez ideal que representa la preponderancia de la «conciencia jurídica formal» a un caso de conducta judicial desviada por «activismo judicial»; o a la inversa, se contrapone el ideal de «juez sustantivista» a un demediado (y desviado) juez ritualista. Estas discusiones entre un modelo ideal y un hombre de paja carecen por completo de interés.

4.3.10.4. Desde la cultura jurídica interna, muchos juristas han digerido mal la constitucionalización del orden jurídico y, en consecuencia, han contribuido a generalizar una actitud crítica que consiste directamente en inventarse la conducta judicial. Parece que estuviéramos rodeados de jueces activistas (desviados, innovadores) evasores de la legalidad y que, como consecuencia de ello, se hubiera incrementado mucho el quantum de arbitrariedad judicial, cuando, me parece, ello no es en absoluto cierto. Que esa imagen no sea cierta no quita que haya ejemplos claros de conducta judicial desviada.

\section{A MODO DE CONCLUSIÓN}

Estas tres objeciones (y sus correspondientes discusiones) que acabamos de referir (la objeción contramayoritaria, la objeción a los derechos como principios y la objeción al judicialismo) ponen de manifiesto la incapacidad de parte de la cultura jurídica interna para adaptarse al nuevo marco generado por la constitucionalización de nuestros órdenes jurídicos. Esta incapacidad se ha traducido en una contumaz erosión de la legitimidad del Estado constitucional, del reconocimiento de su valor y de su racionali- 
dad. Esta contumacia ha acabado por desarmar a muchos juristas a la hora de defender el Estado constitucional contra los embates que, provenientes de la cultura jurídica externa, lo asedian en el presente (y los que lo harán en el futuro). En mi opinión, es urgente construir (y extender) el constitucionalismo jurídico: una teoría del Derecho adaptada a las exigencias del Estado constitucional de Derecho que permita superar de manera definitiva las nostalgias de un pasado jurídico que no regresará y que, además, está siendo mistificado.

\section{BIBLIOGRAFÍA}

Aguiló Regla, J., 2004: La constitución del Estado constitucional, Lima: Palestra.

- 2008: «Darse una constitución, tener una constitución y vivir en constitución», Isonomía, núm. 28, 67-86.

— 2011: «El constitucionalismo imposible de Luigi Ferrajoli», Doxa, núm. 34, 55-71.

- 2012: «Interpretación constitucional. Algunas alternativas teóricas y una propuesta», Doxa, núm. 35, 235-258.

ATIENZA, M., 2017: «Diez tesis sobre el razonamiento judicial», en J. AgUiLó RegLA y P. GRANDEZ (eds.), Sobre el razonamiento judicial. Una discusión con Manuel Atienza, Lima: Palestra.

GuASTINI, R., 2006: Lezioni di teoria del diritto e dello Stato, Torino: G. Giappichelli editore.

LAPORTA, F., 1987: «Sobre el concepto de derechos humanos», Doxa, núm. 4, 23-46.

- 2007: El imperio de la ley. Una visión actual, Madrid: Trotta.

LEÓN, J. J., 2018: «Formalismo y activismo judicial en la argumentación constitucional», ponencia presentada al Seminario de Teoría del Derecho de Fin de Mundo: «Juicio a los tribunales: aplicación, decisión y creación del derecho», Santiago de Chile, agosto.

Merton, R. K., 1938: «Social Structure and Anomie», American Sociological Review, vol. 3 , núm. 5, octubre, 676 y ss.

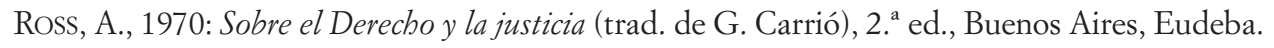

